\title{
Decrease in Serum Interleukin-21 Levels Is Associated With Disease Activity Improvement in Patients With Recent-Onset Rheumatoid Arthritis
}

\author{
O. SGLUNDA ${ }^{1}$, H. F. MANN ${ }^{1}$, H. HULEJOVÁ ${ }^{1}$, O. PECHA ${ }^{2}$, L. PLEŠTILOVÁ ${ }^{1}$, \\ O. RŮŽIČKOVÁ ${ }^{1}$, M. FOJTÍKOVÁ ${ }^{1}$, O. ŠLÉGLOVÁ ${ }^{1}, \breve{S}^{\text {S. FOREJTOVÁ }}{ }^{1}$, K. PAVELKA ${ }^{1}$, \\ J. VENCOVSKÝ ${ }^{1}$, L. ŠENOLT ${ }^{1}$ \\ ${ }^{1}$ Institute of Rheumatology and Clinic of Rheumatology, First Faculty of Medicine, Charles \\ University in Prague, Czech Republic, ${ }^{2}$ Institute of Biophysics and Informatics, First Faculty of \\ Medicine, Charles University in Prague, Czech Republic
}

Received November 18, 2013

Accepted January 23, 2014

On-line April 3, 2014

\begin{abstract}
Summary
Interleukin-21 (IL-21) plays an important role in the pathogenesis of rheumatoid arthritis (RA). The aim of our study was to assess serum levels of IL-21 in patients with recent-onset $\mathrm{RA}$ in relation to disease activity and response to treatment. We analyzed serum levels of IL-21 in 51 RA patients, both before and 12 weeks after the initiation of treatment and in 36 healthy individuals. Disease activity was assessed at baseline and at weeks 12 and 24 using the Disease Activity Score for 28 joints, serum levels of C-reactive protein, and the total swollen joint count. We found that IL-21 levels were not increased in patients with recent-onset RA compared with healthy controls, but they had significantly decreased from baseline to week 12 during treatment. Baseline levels of IL-21 significantly correlated with measures of disease activity ( $p<0.02$ for all). Although IL-21 levels did not predict achievement of remission, decrease in IL-21 levels correlated with improvement in disease activity after 12 weeks $(p<0.02)$ and also after 24 weeks $(p<0.04)$ of treatment. Our data suggest that circulating IL-21 levels may serve as a biomarker of disease activity and better outcome in early phase of RA.
\end{abstract}

\section{Key words}

Interleukin-21 • Rheumatoid arthritis - Disease activity • Remission

\section{Corresponding author}

L. Šenolt, Institute of Rheumatology, Na Slupi 4, 12850 Prague 2,
Czech Republic. Fax: +420 224914451. E-mail: senolt@revma.cz

\section{Introduction}

Rheumatoid arthritis (RA) is a chronic autoimmune disease characterized by formation of autoantibodies and persistent synovitis as well as systemic inflammation (Scott et al. 2010). The etiopathogenesis of the disease remains incompletely understood but it is evident that several pro-inflammatory cytokines are essential in the development of RA via synovial cell activation (Brennan et al. 2008). Major proinflammatory cytokines interleukin-1 (IL-1), IL-6 and tumour necrosis factor- $\alpha$ (TNF- $\alpha$ ) contribute to cartilage destruction and adjacent bone erosions during the course of RA and have become important therapeutic targets. Despite new insights into the pathogenesis of RA, new therapeutic strategies and profound efficacy of biologics in RA, the cause of the disease and long lasting disease remission remain still elusive (Senolt et al. 2009, McInnes et al. 2010). However, some patients respond well or even achieve remission to early therapeutic intervention, whereas others do not or lose the response over time (Saleem et al. 2006). Therefore, there is a need for identification of new biomarkers that would allow regular monitoring of disease activity and/or individualize prognosis, thus enabling early stratification of RA patients according to treatment response (Smolen

PHYSIOLOGICAL RESEARCH • ISSN 0862-8408 (print) • ISSN 1802-9973 (online)

(c) 2014 Institute of Physiology v.v.i., Academy of Sciences of the Czech Republic, Prague, Czech Republic

Fax +420 241062 164, e-mail: physres@biomed.cas.cz, www.biomed.cas.cz/physiolres 
et al. 2010). Furthermore, identification of new biomarkers offers promise for comprehensive understanding to the pathogenesis of RA.

IL-21 is a recently discovered member of the type-I cytokine family, which is synthesized mainly by activated CD4+ T cells (Parrish-Novak et al. 2000). It is involved in a variety of immune system regulating processes, including Th17 cell differentiation, B cell activation, plasma cell differentiation, and immunoglobulin production (Monteleone et al. 2009, Niu et al. 2010, Ozaki et al. 2002). Previous reports have already demonstrated that IL-21 is associated with various autoimmune and inflammatory diseases (summarized in Monteleone et al. 2009). Up-regulation of IL-21 and its receptor has been documented in RA synovial tissue (Jüngel et al. 2004, Kwok et al. 2012). It was demonstrated that IL-21 enhances osteoclastogenesis (Kwok et al. 2012) and that inhibition of IL-21/IL-21 receptor pathway could ameliorate experimental arthritis (Young et al. 2007). In addition, association between plasma levels of IL-21 and disease activity in early RA has been recently observed (Rasmussen et al. 2010).

The aim of our study was therefore to assess serum levels of IL-21 in patients with recent-onset RA before and after treatment and to investigate IL-21 serum levels in relation to disease activity and response to treatment.

\section{Methods}

\section{Patients}

A total of 51 patients (37 women and 14 men) with recent-onset RA were included in the study. Inclusion criteria were as follows: 1) age $>18$ years, 2) fulfilment of the ACR/EULAR 2010 classification criteria for RA at baseline (Aletaha et al. 2010), $3)$ symptom duration of $<6$ months and 4) no or only symptomatic therapy with nonsteroidal antirheumatic drugs prior to baseline. Patients were prospectively followed after initiation of treatment with diseasemodifying antirheumatic drugs (DMARDs) and/or glucocorticoids. The disease activity was assessed using the 28-joint count Disease Activity Score (DAS28-ESR), total swollen joint count (SJC) out of 66, C-reactive protein levels (CRP) and erythrocyte sedimentation rate (ESR). Control group consisted of 36 healthy individuals. The study was approved by the local ethics committee and informed consent was obtained from all patients prior to the initiation of the study.

\section{Laboratory analysis}

Fasting blood samples were collected from all patients at baseline and after 12 weeks. The samples were immediately centrifuged and stored at $-20{ }^{\circ} \mathrm{C}$. Serum levels of C-reactive protein (CRP) were determined by immuno-turbidimetric test using a biochemical analyser (Olympus, model AU 400, Japan). The serum concentration of IL-21 was measured using commercially available ELISA kit (Uscn, Wuhan, China) according to the manufacturer's protocol. The absorbance was measured by an ELISA reader (SUNRISE; Tecan, Salzburg, Austria) using $450 \mathrm{~nm}$ as the primary wavelength. The detection limit (cut-off) was set to $7.2 \mathrm{pg} / \mathrm{ml}$ according to the manufacturer's manual. Values below the detection limit were assigned the same value as the cut-off. Levels of serum anti-cyclic citrullinated peptide antibodies (anti-CCP) and IgM rheumatoid factor (IgM-RF) were measured using standard ELISA assay (Test Line s.r.o., Czech Republic).

\section{Statistical analysis}

The concentration of IL-21 was presented as mean \pm standard deviation. A Kolmogorov-Smirnov test of normality was performed for all variables and their changes. Pearson's product-moment correlations and Spearman's rank correlations were used in cases of normal and non-normal distribution, respectively. Data were adjusted to age and sex. When comparing patients and controls, the independent samples t-test was used for normal variables and the Mann-Whitney test was used as a non-parametric alternative. A two-way analysis of variance (ANOVA) with repeated measures (time $\times$ groups) was conducted to determine the differences between groups of patients sorted by the level of disease activity. A multiple linear regression analysis was performed for changes of DAS28 and total SJC, and appropriate predictors were chosen using a backward stepwise elimination method. $\mathrm{P}$ values below 0.05 were considered to be statistically significant. Statistical analyses were performed using SPSS 17 software (SPSS Inc., Chicago, IL, USA).

\section{Results}

\section{Patients}

Table 1 shows the baseline characteristics of patients and healthy controls included in the study. 29 patients met criteria for highly active disease (DAS28 $>5.1$ ), 20 patients had moderate disease activity 
$(3.2<$ DAS $28 \leq 5.1)$ and 2 patients had low disease activity $(2.6<\mathrm{DAS} 28 \leq 3.2)$ at baseline. Patients included in this study represented extension of our previous work (Andrés Cerezo et al. 2011). DMARDs were administered to 48 patients from baseline. 39 patients were treated with methotrexate (mean weekly dose at week 12: $15 \mathrm{mg}$; range: $10-20 \mathrm{mg}$ ), seven were receiving sulphasalazine and one was on leflunomide. 43 patients were receiving glucocorticoids (mean daily dose at week 12: $5 \mathrm{mg}$ per day; range: $1.25-12.5 \mathrm{mg}$ per day of prednisone or equivalent). Three patients were initially on glucocorticoids only either due to planned gravidity or elevated liver enzymes. After 12 weeks of treatment, a significant reduction in disease activity was observed (DAS28: from $5.4 \pm 1.4$ to $2.7 \pm 1.4$; SJC: from $10.0 \pm 7.7$ to $1.6 \pm 3.1$; CRP: from $19.7 \pm 23.7$ to $5.9 \pm 14.4$; $<<0.0001$ for all comparisons). 46 (90.2\%) patients achieved good or moderate improvement and twenty-six (51\%) reached remission according to the European League Against Rheumatism (EULAR) response criteria (van Gestel et al. 1998) at week 12.

Table 1. Baseline characteristics of the patients with recentonset rheumatoid arthritis (RA) and healthy controls.

\begin{tabular}{lll}
\hline Characteristics & $\begin{array}{c}\text { Recent-onset } \\
\text { RA } \\
(\mathbf{n = 5 1 )}\end{array}$ & $\begin{array}{c}\text { Healthy } \\
\text { controls } \\
(\mathbf{n = 3 6 )}\end{array}$ \\
\hline Gender $(F / M)$ & $37 / 14$ & $24 / 12$ \\
Age $($ years $)$ & $50 \pm 15$ & $44 \pm 15$ \\
CRP $(\mathrm{mg} / \mathrm{l})$ & $19.67 \pm 24.27$ & \\
ESR $\left(\mathrm{mm} / 1^{\text {st }}\right.$ h) & $33.69 \pm 22.58$ & \\
SJC out of 66 & $9.80 \pm 7.81$ & \\
DAS28 score & $5.35 \pm 1.43$ & \\
RF positivity, $n(\%)$ & $33(65)$ & \\
Anti-CCP positivity, $n(\%)$ & $31(61)$ & \\
Drugs $($ DMARDs $/ G C)$ & $48 / 39$ & \\
\hline
\end{tabular}

Anti-CCP, anti-cyclic citrullinated peptide antibody; CRP, C-reactive protein; DAS28 score, disease activity score; DMARDs, disease-modifying antirheumatic drugs; RA, rheumatoid arthritis; ESR, erythrocyte sedimentation rate; $F$, female; GC, glucocorticoids; M, male; MTX, methotrexate; RF, rheumatoid factor; SJC, swollen joints count. Data are expressed as mean (SD).

\section{IL-21 levels and disease activity at baseline}

Although baseline levels of IL-21 in patients with recent-onset RA were comparable to those in healthy controls $(27.98 \pm 39.79$ vs. $27.39 \pm 36.51 \mathrm{pg} / \mathrm{ml}$; $\mathrm{p}=0.888$ ), significant decrease after 12 weeks of treatment (to $8.84 \pm 6.39 \mathrm{pg} / \mathrm{ml}, \mathrm{p}<0.0001$ ) was observed (Fig. 1). In patients with active disease (DAS28>5.1), levels of IL-21 were numerically higher in patients with recent-onset RA $(36.77 \pm 48.03 \mathrm{pg} / \mathrm{ml})$ compared to healthy controls $(p=0.380)$, but the difference did not reach statistical significance. It needs to be emphasized that levels of IL-21 were bellow detection limit in 10 $(27.8 \%)$ healthy control individuals and in 19 (37.3\%) patients with recent-onset RA at baseline, this number increased to $30(58.8 \%)$ patients with recent-onset RA after treatment.

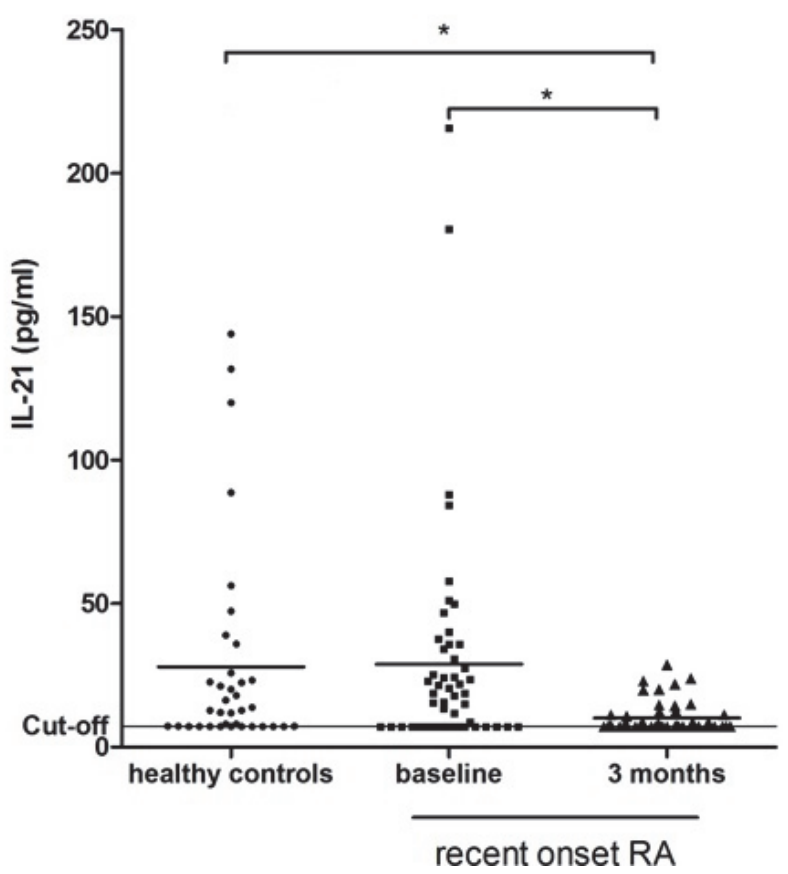

Fig. 1. Serum levels of baseline IL-21 in healthy controls and patients with recent-onset rheumatoid arthritis (RA) before and after 12 weeks of treatment. $* P<0.05$.

Using univariate analysis, baseline levels of IL-21 correlated positively with DAS28 ( $\mathrm{r}=0.447$, $\mathrm{p}=0.001)$, CRP levels $(\mathrm{r}=0.356, \mathrm{p}=0.012)$ and total SJC $(r=0.346, p=0.015)$ (Fig. 2A). However, after 12 weeks of treatment, the levels of IL-21 did not correlate with any of these parameters (DAS28: $p=0.946$, CRP: $p=0.189$, SJC: $p=0.678)$. The lack of correlation after treatment could be affected by the fact that IL-21 levels were below the detection limit in more than half of the patients. There was also no correlation between baseline serum levels of IL-21 and clinical markers of disease activity after 12 or 24 weeks of treatment (DAS28, CRP, SJC: $p>0.200$ for all). Serum levels of IL-21 were not affected by age, sex or symptom duration and did not correlate with 
autoantibody profile. Decrease of IL-21 levels was not affected by type or dose of administrated drugs (data not shown).

\section{Decrease of IL-21 and disease activity improvement}

As we found significant decrease of IL-21 after the treatment and positive association between IL-21 and disease activity at baseline, we were curious whether changes in IL-21 levels could be associated with disease activity improvement. Interestingly, we found that decrease in IL-21 levels correlated positively with clinical improvement as assessed by changes in DAS28 $(r=0.336$, $\mathrm{p}=0.018)$ and serum levels of CRP $(\mathrm{r}=0.355, \mathrm{p}=0.012)$, but not SJC ( $r=0.240, p=0.099)$, over the first 12 weeks (Fig. 2B). Furthermore, changes in IL-21 serum levels over the first 12 weeks were associated with improvement in DAS28 $(\mathrm{r}=0.400, \mathrm{p}=0.008), \quad \mathrm{CRP}$ $(\mathrm{r}=0.385, \mathrm{p}=0.010)$ and also in total SJC $(\mathrm{r}=0.324$, $\mathrm{p}=0.032$ ) from baseline to week 24 (Fig. 2C).

In addition, levels of IL-21 at baseline were inversely associated with decrease of CRP levels $(\mathrm{r}=-0.356, \mathrm{p}=0.012)$ and DAS28 $(\mathrm{r}=-0.339, \mathrm{p}=0.017)$, but not of total SJC $(r=-0.262, p=0.072)$ between baseline and 12 weeks, and also with decrease of CRP $(\mathrm{r}=-0.384, \mathrm{p}=0.010)$, DAS28 $(\mathrm{r}=-0.392, \mathrm{p}=0.009)$ and also of total SJC $(\mathrm{r}=-0.332, \mathrm{p}=0.028)$ between baseline and 24 weeks. However, baseline levels of IL-21 did not predict achievement of remission, since there were no significant differences in baseline levels of IL-21 between patients who achieved remission and those with moderate or high disease activity at week $12(29.22 \pm 39.37$ vs. $28.44 \pm 40.64 \mathrm{pg} / \mathrm{ml}, \mathrm{p}=0.95)$.
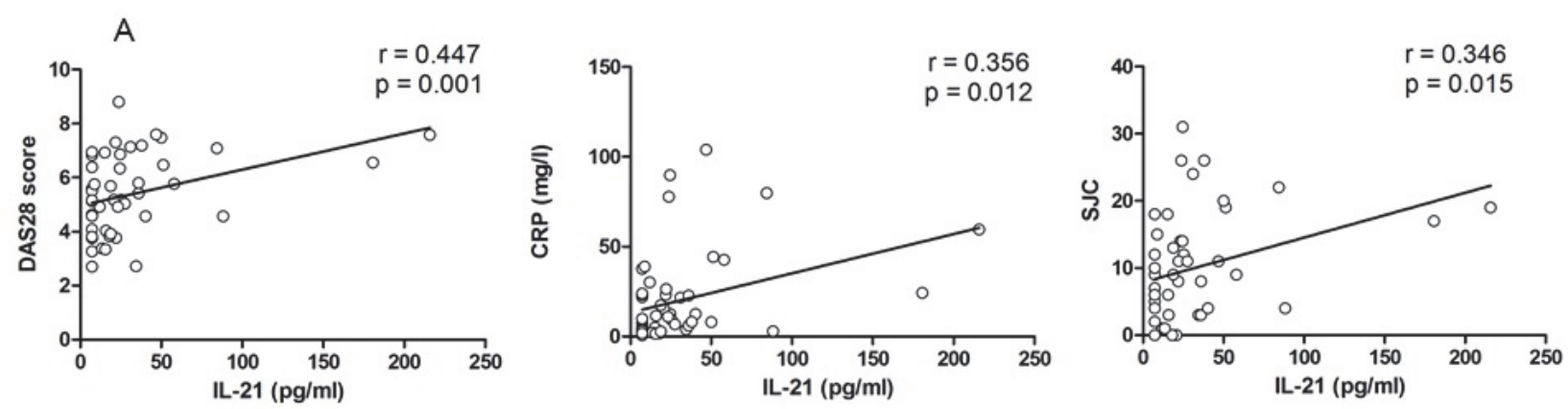

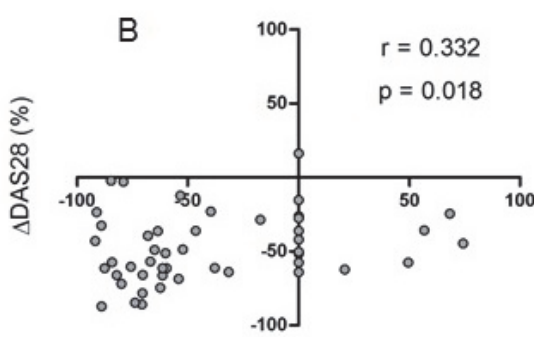

$\Delta \mathrm{lL}-21(\%)$

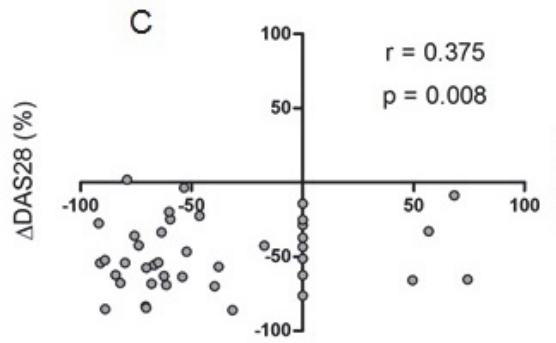

$\Delta \mathrm{IL}-21(\%)$

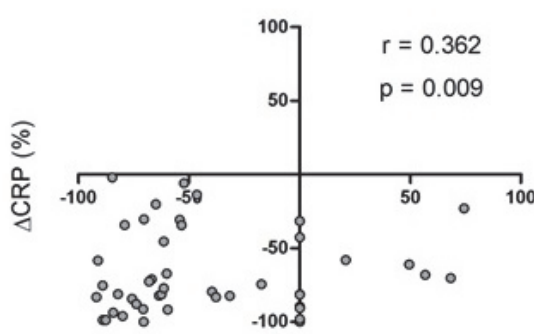

$\Delta \mathrm{LL}-21(\%)$

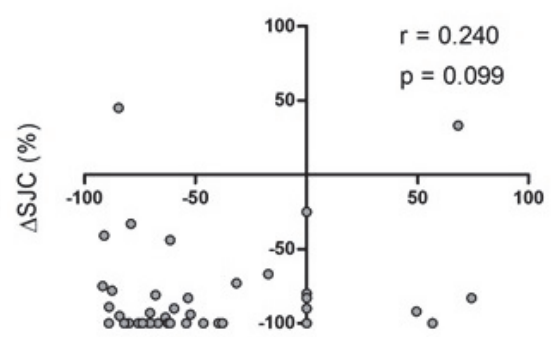

$\Delta \mathrm{IL}-21(\%)$

Fig. 2. Association between serum levels of IL-21 and disease activity in patients with recent-onset rheumatoid arthritis (RA) at baseline (A) and association of changes in IL-21 levels between baseline and week 12 with disease activity improvement after 12 (B) and 24 (C) weeks of treatment. DAS28, disease activity score; CRP, C-reactive protein; SJC, swollen joint count out of 66. 
Multiple linear regression analysis revealed that improvement in DAS28 over 12 weeks ( $p=0.048$ vs. $\mathrm{p}=0.099$ ) was easier to predict by baseline CRP than IL-21 levels (Table 2), however in predicting DAS28 improvement over 24 weeks, IL-21 levels $(p=0.166)$ performed better than baseline CRP $(p=0.966)$, although both were found insignificant (Table 3 ).

Table 2. Multiple linear regression model for change $(\Delta)$ in DAS28 between baseline and week 12 .

\begin{tabular}{lcccc}
\hline $\begin{array}{c}\text { Explanatory } \\
\text { Variable }\end{array}$ & $\boldsymbol{4}$ & $\mathbf{p}$ & t-value & SE \\
\cline { 2 - 5 } & $\boldsymbol{4}$ & 0.000 & 4.104 & 0.015 \\
$\Delta$ CRP $^{\mathrm{a}}$ & 0.061 & $0.000 \mathrm{tcome}$ \\
baseline CRP & 0.024 & 0.048 & 2.031 & 0.012 \\
\hline
\end{tabular}

Excluded predictor: baseline IL-21 $(p=0.099) .{ }^{a}$ CRP change between weeks 0 and 12 .

Table 3. Multiple linear regression model for change $(\Delta)$ in DAS28 between baseline and week 24 .

\begin{tabular}{lcccc}
\hline \multirow{2}{*}{$\begin{array}{l}\text { Explanatory } \\
\text { Variable }\end{array}$} & \multicolumn{4}{c}{ Outcome } \\
\cline { 2 - 5 } & $\boldsymbol{\beta}$ & $\mathbf{p}$ & $\mathbf{t}$-value & $\mathbf{S E}$ \\
\hline$\Delta \mathrm{CRP}^{\mathrm{a}}$ & 0.049 & 0.000 & 5.461 & 0.009 \\
\hline
\end{tabular}

Excluded predictors: baseline IL-21 $(p=0.166)$ and baseline CRP $(p=0.966) .{ }^{a}$ CRP change between weeks 0 and 12 .

\section{Discussion}

In this study we demonstrated, that although not significantly different from healthy controls, serum levels of IL-21 correlated with disease activity in patients with recent-onset RA. Furthermore, we showed that initiation of immunosuppressive treatment contributed to significant decrease of IL-21 levels after 12 weeks, which was associated with later clinical improvement.

Although our cohort also consisted of treatment naïve patients with symptom duration of less than six months, we found that IL-21 levels were not elevated in RA patients compared to healthy controls, a finding which is in contrast to the results of other authors (Rasmussen et al. 2010). There are some possible explanations for this finding. Firstly, significantly more cells with IL-21 producing capacity were demonstrated in synovial fluid compared to peripheral blood (Young et al. 2007). Furthermore, increased expression of IL-21 receptor (Jüngel et al. 2004) and IL-21 concentration (Young et al. 2007, Kwok et al. 2012) at the sites of inflammation support the hypothesis, that local, rather than systemic, production of IL-21 contributes to the pathogenesis of RA. It has been recently reported that circulating IL-21 levels were comparable among patients with very early RA, established RA and healthy controls (Moura et al. 2011, Zivojinovic et al. 2012), and these findings are in agreement with our results. In addition, we found that IL-21 levels significantly decreased after the initiation of treatment, which conforms with a recently described significant decrease of serum IL-21 levels in patients with RA responding to TNF blocking therapy (Chen et al. 2011). Post-treatment levels of IL-21 in our study were even lower than those in healthy controls, which may suggest suppression of immune cells producing IL-21. Based on our data it can be speculated that good therapeutic response is associated with reduced Th17 response leading to a further decrease of immune cells producing IL-21.

We demonstrated significant correlation between circulating IL-21 and clinical, as well as laboratory, measures of disease activity in patients with recent-onset RA, which is in agreement with published data (Rasmussen et al. 2010). Although baseline serum levels of IL-21 did not predict achievement of remission or disease activity improvement better than CRP, we were the first to show that higher levels of IL-21 at baseline and decrease of IL-21 after treatment significantly associated with disease activity improvement over time. This association between IL-21 and disease activity provides further evidence to support the role of IL-21 in the pathogenesis of RA. In line with this, other authors recently found rapid radiographic progression in patients with RA with detectable levels of IL-21 (Gottenberg et al. 2012).

In conclusion, our results show that, although serum levels of IL-21 were not elevated in patients with recent-onset RA compared with healthy controls, baseline levels of IL-21 correlated with disease activity and significantly decreased after conventional treatment. The decrease of IL-21 concentration correlated with disease activity improvement over time. This data further supports the role of IL-21 in RA pathology.

\section{Conflict of Interest}

There is no conflict of interest. 


\section{Acknowledgements}

This work was supported by the project of Ministry of Health, Czech Republic for conceptual development of research organization 023728, project number NT 12437-5 and SVV project number 264511.

\section{References}

ALETAHA D, NEOGI T, SILMAN AJ, FUNOVITS J, FELSON DT, BINGHAM CO 3RD, BIRNBAUM NS, BURMESTER GR, BYKERK VP, COHEN MD, COMBE B, COSTENBADER KH, DOUGADOS M, EMERY P, FERRACCIOLI G, HAZES JM, HOBBS K, HUIZINGA TW, KAVANAUGH A, KAY J, KVIEN TK, LAING T, MEASE P, MÉNARD HA, MORELAND LW, NADEN RL, PINCUS T, SMOLEN JS, STANISLAWSKA-BIERNAT E, SYMMONS D, TAK PP, UPCHURCH KS, VENCOVSKY J, WOLFE F, HAWKER G: 2010 rheumatoid arthritis classification criteria: an American College of Rheumatology/European League Against Rheumatism collaborative initiative. Ann Rheum Dis 69: 1580-1588, 2010.

ANDRÉS CEREZO L, MANN H, PECHA O, PLEŠTILOVÁ L, PAVELKA K, VENCOVSKÝ J, SENOLT L: Decreases in serum levels of S100A8/9 (calprotectin) correlate with improvements in total swollen joint count in patients with recent-onset rheumatoid arthritis. Arthritis Res Ther 13: R122, 2011.

BRENNAN FM, MCINNES IB: Evidence that cytokines play a role in rheumatoid arthritis. $J$ Clin Invest 118: 3537 3545, 2008.

CHEN DY, CHEN YM, CHEN HH, HSIEH CW, LIN CC, LAN JL: Increasing levels of circulating Th17 cells and interleukin-17 in rheumatoid arthritis patients with an inadequate response to anti-TNF- $\alpha$ therapy. Arthritis Res Ther 13: R126, 2011.

GOTTENBERG JE, DAYER JM, LUKAS C, DUCOT B, CHIOCCHIA G, CANTAGREL A, SARAUX A, ROUXLOMBARD P, MARIETTE X: Serum IL-6 and IL-21 are associated with markers of B cell activation and structural progression in early rheumatoid arthritis: results from the ESPOIR cohort. Ann Rheum Dis 71: 12431248, 2012.

JÜNGEL A, DISTLER JH, KUROWSKA-STOLARSKA M, SEEMAYER CA, SEIBL R, FORSTER A, MICHEL BA, GAY RE, EMMRICH F, GAY S, DISTLER O: Expression of interleukin-21 receptor, but not interleukin-21, in synovial fibroblasts and synovial macrophages of patients with rheumatoid arthritis. Arthritis Rheum 50: 1468-1476, 2004.

KWOK SK, CHO ML, PARK MK, OH HJ, PARK JS, HER YM, LEE SY, YOUN J, JU JH, PARK KS, KIM SI, KIM HY, PARK SH: Interleukin-21 promotes osteoclastogenesis in humans with rheumatoid arthritis and in mice with collagen-induced arthritis. Arthritis Rheum 64: 740-751, 2012.

MCINNES IB, O'DELL JR: State-of-the-art: rheumatoid arthritis. Ann Rheum Dis 69: 1898-1906, 2010.

MONTELEONE G, SARRA M, PALLONE F: Interleukin-21 in T cell-mediated diseases. Discov Med 8: 113-117, 2009.

MOURA RA, CASCÃO R, PERPÉTUO I, CANHÃO H, VIEIRA-SOUSA E, MOURÃO AF, RODRIGUES AM, POLIDO-PEREIRA J, QUEIROZ MV, ROSÁRIO HS, SOUTO-CARNEIRO MM, GRACA L, FONSECA JE: Cytokine pattern in very early rheumatoid arthritis favours B-cell activation and survival. Rheumatology (Oxford) 50: 278-282, 2011.

NIU X, HE D, ZHANG X, YUE T, LI N, ZHANG JZ, DONG C, CHEN G: IL-21 regulates Th17 cells in rheumatoid arthritis. Hum Immunol 71: 334-341, 2010.

OZAKI K, SPOLSKI R, FENG CG, QI CF, CHENG J, SHER A, MORSE HC 3RD, LIU C, SCHWARTZBERG PL, LEONARD WJ: A critical role for IL-21 in regulating immunoglobulin production. Science 298: 1630-1634, 2002. 
PARRISH-NOVAK J, DILLON SR, NELSON A, HAMMOND A, SPRECHER C, GROSS JA, JOHNSTON J, MADDEN K, XU W, WEST J, SCHRADER S, BURKHEAD S, HEIPEL M, BRANDT C, KUIJPER JL, KRAMER J, CONKLIN D, PRESNELL SR, BERRY J, SHIOTA F, BORT S, HAMBLY K, MUDRI S, CLEGG C, MOORE M, GRANT FJ, LOFTON-DAY C, GILBERT T, RAYOND F, CHING A, YAO L, SMITH D, WEBSTER P, WHITMORE T, MAURER M, KAUSHANSKY K, HOLLY RD, FOSTER D: Interleukin 21 and its receptor are involved in NK cell expansion and regulation of lymphocyte function. Nature 408: 57-63, 2000.

RASMUSSEN TK, ANDERSEN T, HVID M, HETLAND ML, HØRSLEV-PETERSEN K, STENGAARDPEDERSEN K, HOLM CK, DELEURAN B: Increased interleukin 21 (IL-21) and IL-23 are associated with increased disease activity and with radiographic status in patients with early rheumatoid arthritis. $J$ Rheumatol 37: 2014-2020, 2010.

SALEEM B, NIZAM S, EMERY P: Can remission be maintained with or without further drug therapy in rheumatoid arthritis? Clin Exp Rheumatol 24: 33-36, 2006.

SCOTT DL, WOLFE F, HUIZINGA TW: Rheumatoid arthritis. Lancet 376: 1094-1108, 2010.

SENOLT L, VENCOVSKÝ J, PAVELKA K, OSPELT C, GAY S: Prospective new biological therapies for rheumatoid arthritis. Autoimmun Rev 9: 102-107, 2009.

SMOLEN JS, ALETAHA D, BIJLSMA JW, BREEDVELD FC, BOUMPAS D, BURMESTER G, COMBE B, CUTOLO M, DE WIT M, DOUGADOS M, EMERY P, GIBOFSKY A, GOMEZ-REINO JJ, HARAOUIB, KALDEN J, KEYSTONE EC, KVIEN TK, MCINNES I, MARTIN-MOLA E, MONTECUCCO C, SCHOELS M, VAN DER HEIJDE D; T2T Expert Committee: Treating rheumatoid arthritis to target: recommendations of an international task force. Ann Rheum Dis 69: 631-637, 2010.

VAN GESTEL AM, HAAGSMA CJ, VAN RIEL PL: Validation of rheumatoid arthritis improvement criteria that include simplified joint counts. Arthritis Rheum 41: 1845-1850, 1998.

YOUNG DA, HEGEN M, MA HL, WHITTERS MJ, ALBERT LM, LOWE L, SENICES M, WU PW, SIBLEY B, LEATHURBY Y, BROWN TP, NICKERSON-NUTTER C, KEITH JC JR, COLLINS M: Blockade of the interleukin-21/interleukin-21 receptor pathway ameliorates disease in animal models of rheumatoid arthritis. Arthritis Rheum 56: 1152-1163, 2007.

ZIVOJINOVIC SM, PEJNOVIC NN, SEFIK-BUKILICA MN, KOVACEVIC LV, SOLDATOVIC II, DAMJANOV NS: Tumor necrosis factor blockade differentially affects innate inflammatory and Th17 cytokines in rheumatoid arthritis. J Rheumatol 39: 18-21, 2012. 